\title{
EDITORIAL
}

\section{Proceso enseñanza aprendizaje: Desde la sociedad para servir a la sociedad}

\section{Teaching learning process: from society to serve society}

\section{Frank Lizaraso Caparól,a,b, Napoleón Paredes Pérez ${ }^{2, c}$}

La determinación de los Modelos Enseñanza-Aprendizaje en los estudiantes de la Salud es fundamental para seleccionar las Metodologías de enseñanza más adecuada.

El concepto: "aprender a aprender", definido como el conocimiento y destreza necesarios para aprender con efectividad en cualquier situación en que uno se encuentre, permitió el desarrollo del planteamiento de las teorías de estilos de aprendizaje (1).

Los estilos de aprendizaje, son los rasgos cognitivos, afectivos y fisiológicos que sirven de indicadores relativamente estables de cómo los estudiantes perciben, interaccionan y responden en sus ambientes de aprendizaje $(2,3)$.

Es importante el conocimiento y comprensión por parte del estudiante de su propio estilo de aprendizaje, esto le permitirá tomar conciencia de las estrategias cognitivas que emplea y de cuáles son las más adecuadas en cada caso; además, se trata de uno de los factores claves para desarrollar su capacidad de "aprender a aprender" (4).

Los estudiantes de Medicina de diversas Facultades de Medicina, tienen preferencia por los estilos reflexivo y teórico, los que muestran bastante estabilidad a lo largo de su formación académica y que son, aparentemente, independientes de los contextos geográficos y curriculares en que se encuentran inmersos (1).

A los reflexivos les gusta considerar las experiencias y observarlas desde diferentes perspectivas, recogen datos y los analizan con detenimiento antes de llegar a alguna conclusión. Disfrutan observando la actuación de los demás y sólo intervienen cuando se han "adueñado" de la situación (4).

El estilo teórico, permite observar en el estudiante características como: metódico, lógico, objetivo, crítico, estructurado, que tiene afán por la perfección, intentando comprender todo dentro de marcos globales, lógicos y coherentes (5).

En nuestra Facultad, estamos consiguiendo progresivamente que el estudiante demuestre lo aprendido, lo que evidenciamos a través del análisis y exposición que hacen de los casos clínicos y la sustentación de los mismos.

De esta manera, los docentes pueden explotar los estilos preferenciales y ayudar a los estudiantes a aprovecharlos mejor (6)

La evidencia clásica postula que los individuos con perfiles divergente o acomodador pueden ser inadecuados para el pensamiento científico y la toma de decisiones, ya que entre sus características suelen ser más intuitivos y con poca habilidad analítica. Se considera que estos candidatos se vuelcan más al arte, la literatura, la psicología o la comunicación $(7,8)$. 


\section{En conclusión:}

- $\quad$ Es necesario considerar al estudiante como eje del Modelo Enseñanza-Aprendizaje.

- El Docente debe ser capacitado en Docencia Universitaria y en el Modelo elegido.

- $\quad$ El Modelo a elegir debería tener como base el método científico.

- La investigación debe ser el eje central del Modelo Enseñanza-Aprendizaje.

- El Modelo Enseñanza-Aprendizaje debe desarrollar el análisis, síntesis y evaluación del conocimiento.

- La evaluación del estudiante debe ser parte del Modelo Enseñanza-Aprendizaje, valorando lo procedimental y lo actitudinal.

La evidencia será el posicionamiento del egresado. Por eso decimos: "Formamos desde la sociedad para servir a la sociedad".

\section{REFERENCIAS BIBLIOGRÁFICAS}

1. Díaz-Véliz G, Mora S, Lafuente-Sánchez JV, Gargiulo PA, Bianchi R y col. Estilos de aprendizaje de estudiantes de medicina en universidades latinoamericanas y españolas: relación con los contextos geográficos y curriculares. Educ Med 2009; 12 (3): 183-194.

2. Escanero JF, González-Haro C, Ezquerra L, Borque L. Diseño e implementación de una práctica de metacognición en la asignatura de Fisiología Humana (Facultad de Medicina). Educ Med 2009; 12: 47-53.

3. Soria M, Guerra M, Lou M, Pié J, Escanero JF. Estilos de aprendizaj e de los estudiantes de ciencias de la salud. Educ Med 2005; 8: 145.

4. Fortoul T, Varela M, Avila M y col. Factores que influyen en los estilos de aprendizaje en el estudiante de medicina. Rev de la Educ Superior 2006; 138: 55-62.
5. Rosales-Gracia S, Gómez-López VM, Gómez-Garza A. Comparación del rendimiento académico de estudiantes de medicina según su estilo de aprendizaje predominante. Archivos en Medicina Familiar 2010; 12(4): 128'134.

6. Dolmans DHJM, Wolfhagen IHAP. The relationship between learning style and learning environment. Med Educ 2004; 38: 800-4.

7. Kolb A, Kolb D. The Kolb Learning Style Inventory Version 3.1. Technical Specifications. Cleveland, OH: Case Western Reserve University, 2005.

8. Borracci R, Arribalzaga E. Estilos de aprendizaje de kolb en estudiantes de medicina. MEDICINA (Buenos Aires) 2015; 75: 73-80

\section{Editor Horizonte Médico}

Doctor en Medicina. Médico Cirujano Plástico

Decano de la Facultad de Medicina Humana de la USMP. Lima, Perú.

Director Horizonte Médico

Director del Instituto de Investigación de la Facultad de Medicina Humana de la USMP Lima, Perú 